\title{
An overview of tuberculosis in Animals in Nigeria
}

\author{
Ibrahim, S. ${ }^{1}$; Kaltungo, B. Y. ${ }^{2}$; Buhari H. U. ${ }^{3}$; Baba, A. Y. ${ }^{4}$; Saidu, S. N. A. ${ }^{1}$;ohammed, F.U. ${ }^{2}$ \\ and Dahiru, M. H. \\ ${ }^{\mathbf{1}}$ Department of Veterinary Medicine, Ahmadu Bello University, Zaria, Nigeria. \\ ${ }^{2}$ Veterinary Teaching Hospital, Ahmadu Bello University, Zaria, Nigeria. \\ ${ }^{3}$ Samaru College of Agriculture, Ahmadu Bello University, Zaria, Nigeria. \\ ${ }^{4}$ Department of Veterinary Medicine, University of Ilorin, Nigeria. \\ ${ }^{5}$ Department of Veterinary Services, Ministry of Agriculture and Natural Resources, Katsina State, Nigeria. \\ *Corresponding Author, Ibrahim, S., E-Mail: sihadejia@gmail.com
}

\begin{abstract}
Tuberculosis of animal origin is currently in the increase, especially in the developing countries like Nigeria where animals and man share microenvironment together coupled with lack of proper control measures. The disease due to Mycobacterium bovis has zoonotic implication. Systematic methodology was adopted where peer-reviewed, scholarly journals in Scopus, PubMed, Google search engines were used. The articles used were on studies in Nigeria and elsewhere and that were published in Nigeria and other parts of the world. It is therefore important to have adequate control programmes, proper food hygienic practices and collaborations between Veterinary and Human Medical Personnel in order to control and later eradicate the disease. The objective of this manuscript was to review the work of earlier workers on tuberculosis in animals and to a certain extent its impact on humans. There is also the need to educate the populace on the dangers of the disease in both human and animals.
\end{abstract}

Keywords: Abattoir, Animals, Humans, Livestock, MTBC, Tuberculosis.

\section{Review Article:}

DOI:https://dx.doi.org/10.21608/javs.20 21.74906 .1078

Received :02 May, 2021.

Accepted :03 June, 2021.

Published in July, 2021.

This is an open access article under the term of the Creative Commons Attribution 4.0 (CC BY) International License. To view a copy of this license, visit:

http://creativecommons.org/licenses/by/4.0/

\section{INTRODUCTION}

Tuberculosis is still a big problem in many developing countries, with scanty epidemiological assessment on the impact of the disease on livestock and human health (Grange 2001). Bovine TB infects a higher proportion of exotic dairy breeds (Bos taurus) than indigenous zebu cattle (Bos indicus) and crossbred cattle (Cosivi et al., 1998).

In sub-Saharan Africa bTB is endemic largely because of lack of financial resources which makes control programs ineffective. The disease has significant effects on the livelihoods of pastoralist communities with negative impacts on their animal health, welfare and animal trade at international level. Very few African countries followed adequate control/eradication programs, the majority of the countries including Nigeria have inadequate control bTB or not carried out at all (El-Sayed et al., 2016). Mostly, postmortem examination of carcasses without systematic antemortem examination without applying of test-and-slaughter policy is the only current bTB control strategy being applied in Nigeria.

Several studies carried out by various workers (Ameen et al., 2008; Cadmus et al., 2009; Raufu and Ameh, 2010; Damina et al., 2011; Ahmad et al., 2017) have undertaken studies at Nigerian abattoirs reported bTB in cattle based on macroscopic lesions ranging from $0.54 \%-6.1 \%$, indicating an increased trend in the prevalence of the disease. Reports in other animals was very scanty due lack of laboratories and poor case management (Ibrahim 2016) as such analyses to confirm infection in animals found with gross lesions are rarely performed except for research purposes.

\section{Genus Mycobacterium}

TB is caused by members of the genus Mycobacterium that contains approximately eighty-five different species. Mycobacteria are mostly aerobic, though some can be microaerophilic, nonchromogenic, rod-shaped and non-motile bacteria. The acid-fast staining reaction is the primary test for 


\section{An overview of tuberculosis in Animals in Nigeria}

identifying mycobacteria since the cells are resistant to decolourisation with a dilute mineral acid (or acidalcohol solution) after staining with an arylmethane dye, such as fuchsin (Ziehl-Neelsen staining) (Grange, (1996); Collins et al., (1997); Rastogi et al., (2001); European Food Safety Authority, (2003). "Mycobacterium tuberculosis complex" (MTBC) has seven approved members and these are Mycobacterium tuberculosis, Mycobacterium bovis, Mycobacterium bovis BCG, Mycobacterium africanum, Mycobacterium microti, Mycobacterium tuberculosis sbsp. Canetti and Mycobacterium bovis sbsp. Caprae (Haddad et al., (2004); Collins, (2011). Four members of this group cause human tuberculosis and are $M$. bovis, $M$. tuberculosis, M. africanum and $M$ Canetti (Collins et al., (1997); Collins, (2011). Members of the MTBC are extremely similar genetically 24 having at least 99.9\% similarity on the nucleotide level and an identical 16rRNA sequence (Brosch et al., (2002).

\section{Mycobacteria Structure}

Mycobacteria are similar to other bacteria in many respects except for a unique cell wall that is made up of four parts (Figure 1). The first part is a peptidoglycan layer that is similar to that found on other bacterial species. The second layer contains arabinogalactan, which is made up of branched macromolecules of arabinose and galactose (Grange, (1996). The third layer, which contributes to the thickness of mycobacterial cell walls, is made of mycolic acids that are long branched chains of fatty acids with differing 50 and 30 carbon atom lengths. The mycolic acids are responsible for the acid-fast staining reaction of mycobacteria cells (Thoen and Steele, (1995); Grange, (1996). The fourth, outer, layer consists of a mixture of lipids and related compounds such as trehalose-containing (glycolipids and peptidoglycolipids called mycosides. Trehalosecontaining glycolipids include a "cord-factor" compound that was previously believed to be responsible for the "serpentine cords" of virulent MTBC but this was later proved to be inaccurate (Grange, 1996).

The mycosides on the outer layer of the cell wall have similar functions as the capsule in capsulated bacteria and allow mycobacterial cells to survive in less-than-ideal conditions. M. bovis may survive depending on the environment, specifically exposure to direct sunlight, for period of time ranging from several days to months in soil, on pastures or in faeces leading to increased risk of infection $\left(\mathrm{O}^{\text {ee }}\right.$ Reilly and Daborn, 1995). The mycosides also allow for certain mycobacteria, such as those in the MAC complex, to be subdivided due to an agglutination reaction to specific antisera. The thick layer of mycosides on some species of mycobacteria gives them a smooth colony when grown on solid media and in the case of MAC the colonial morphology can be correlated to virulence with transparent and rough colony forming strains being more virulent than opaque and intermediate colony forming strains (Kuze and Uchihira, (1984); European Food Safety Authority, (2003). Another benefit of the presence of mycosides is that they may provide protection to intracellular organisms against the ,cidal effects of intermediate oxygen metabolites" (Grange, (1996).

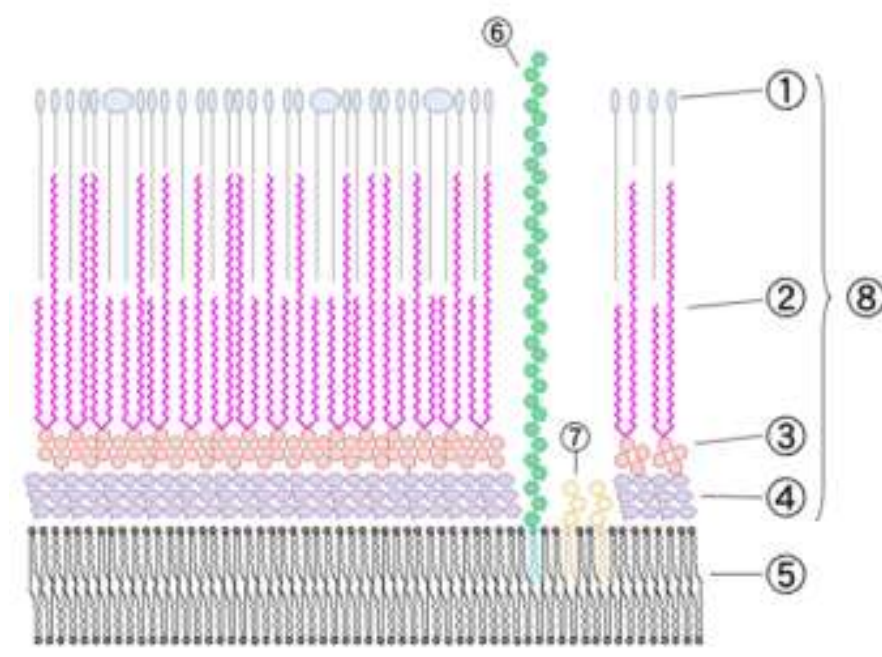

Fig. 1: Structure of Mycobacterium: 1. Outer lipid, 2. Mycolic acid, 3. Polysaccharides (arabinglycan), 4. Peptidoglycan, 5. Plasma membrane, 6 Lipoarabinonnan(LAM),7. Phosphatidylinositolmannoside, 8. Cell wall (Grange et al., (1996).

\section{Characteristics of livestock production in Nigeria}

In order to understand the epidemiology of tuberculosis in animals, a good comprehension of the husbandry and management systems of the animals is important. Livestock production in Nigeria especially that as practiced by the pastoralists, is characterized by extensive management system while the animals under the elite herds are being managed partially under semiintensive system (Saidu, et al., 1991; Danbirni, 2018). This involves the cattle and to a certain extent sheep being moved from one place to another. Should these herds be infected with any disease, they stand the chance to spread such diseases (Kaltungo, 2013; Buhari, 2014). As for small ruminants most of them are under small holder production system with the owners keeping few animals under extensive management system (Aliyu, 1990).

Pigs are managed in two ways with the indigenous ones being under extensive system while those under commercial system are managed under intensive to semi-intensive management system Camels are kept under extensive system (Kaltungo, 2018b). As for horses there are three categories which 
include polo, racing and ceremonial ones (Musa, 2013; Baba, 2016). The polo and racing horses are to a large extent kept under semi-intensive system while the ceremonial ones are on extensive management system (Baba, 2016; 2019). With regard to poultry, especially chickens, turkey and ducks, there are those that are under extensive system like those under village level and semi-urban areas while commercial poultry are strictly under intensive management system. Dogs and cats are usually under the care of their owners at home with some of the dogs under leach (Lawal, 2019).

There are also dogs under the management of hunters, butchers and those under villages with the owners keeping them for leisure, hunting and security purposes. Dogs can acquire TB through feeding on contaminated meat as occasioned by dogs owned by butchers and hunters (Lawan et al., 2010). As for cats, they are always indoors under the care of their owners. The only possibility for cats to become infected is by them eating from wastes left over by their owners. Should such wasters contain contaminated materials with Mycobacterium species such cats could come down with the disease.

The Nigerian cattle sector is the largest component of the total cash income contributing an average of 9\% of the total Gross Domestic Product (GDP) of the total livestock cash income (FAO, 2019). For example, in Nigeria, $80 \%$ of the livestock production is in the hands of pastoralists (Usman etal., 2011). The poor educational standard of pastoralists along with many of the rural and semiurban dwellers who keep livestock has resulted in many diseases being stumbling block on the way to improved livestock production in Nigeria (Saidu $\boldsymbol{e t}$ al., 1991; Kaltungo, 2013; Yakubu, 2016). For example, Danbirni (2016) has given the seroprevalence of bovine tuberculosis in Adamawa and Taraba States, Nigeria to be $8.4 \%$ and $3.2 \%$ respectively while Ibrahim (2016) gave the seroprevalences in Bauchi and Gombe States to be $10.5 \%$ and $13.73 \%$ respectively. With an estimated cattle population of over 15.24 million in Nigeria, the population of cattle exposed to bovine tuberculosis (bTB) stands to be high.

\section{Distribution of Tuberculosis in Nigeria}

Bovine tuberculosis has been reported in almost all the states of Nigeria Alhaji, (1976); Igbokwe et al., (2001); Cadmus et al., (2006); Nwanta et al., (2011); Abubakar et al., (2012), Ahmad, (2015); Saidu et al., (2017); Danbirni, (2016); Ibrahim, (2016). Not only that Nigeria has been ranked third to fifth among the high TB burden countries in the world along other countries like India, Indonesia, and China, and ahead of Pakistan and South Africa (WHO, 2017). Alan et al., (2016), in a recent large-scale study on human patients that had TB and HIV in Nigeria reported that $22 \%$ of the subjects had co-infection rates of $8.3 \%, 6.7 \%$ and $7.6 \%$ for 2013 , 2014 and 2015 respectively. Their studies further indicated that the highest rate $(10.3 \%)$ of co-infection was in the Southeastern region of Nigeria followed by Southwestern region with $8.3 \%$. These high infection rates, if compared with what obtains in the developed world can be said to be due to poor to inadequate surveillance and disease control programmes in the country Alan et al., (2016). The human cases of tuberculosis associated with $M$. bovis infection in Nigeria could be said to be as a result of close association of livestock with humans, especially as to the way animal housing is close to that of the livestock owners (Kaltungo, 2018a, Baba, 2019).

\section{Reports from North Western Nigeria}

One of the earliest workers who carried out research on bovine tuberculosis (bTB) in the North Western part of Nigeria is Alhaji (1976) as he surveyed the prevalence of the disease in the whole North Western part of the country. Other workers include Shehu (1988), Ahmad (2015), Danbirni (2016) and Ibrahim (2016). Alhaji (1976) reported a prevalence of $4 \%$. Similarly, Shehu (1988), who conducted a survey of the prevalence of the disease in pastoralists herds in the then Zaria Local Government Area of Kaduna State detected $11.8 \%$ of the herds tested to be positive for tuberculosis using tuberculin test. Furthermore, out of the 90 milk samples from these herds which he tested only 1 ((1.1\%) yielded Mycobacterium species. Similarly, of the 29 sputum samples from the herdsmen he tested for Mycobacterium species, only 4 (13.8\%) were positive for the organism.

Ahmad (2015), using abattoir samples from Gusau abattoir in Zamfara State, Nigeria, confirmed the existence of $M$. bovis and other members of the MTC in cattle in Nigeria. In this study, M. bovis was found to have isolation rates of $88.2 \%$ while $M$. caprae and M. tuberculosis had $8.8 \%$ and $2.9 \%$ isolation rates respectively. He observed that the finding of $M$. tuberculosis in the tissues of the cattle examined to account for a possible interaction of the pathogen from humans to cattle indicating a reverse zoonotic transmission. However, Garba et al., (2010) in Kebbi State while reporting on common diseases of sheep and goats did not indicate finding cases of TB in these animals. The reason could be that only clinical findings were used to diagnose the cases in the study. Similarly, Abubakar et al., (2014) in a retrospective study of tuberculosis in slaughtered camels at Kano abattoir, Kano State from 2004 to 2013 examined 65,277 camels out of which only $750(1.2 \%)$ had lesions compatible with TB. They gave the distribution of the lesions in 


\section{An overview of tuberculosis in Animals in Nigeria}

the camels to be lungs (64.4\%), lymph nodes (17.7\%), liver $(7.5 \%)$, intestines $(5.7 \%)$, kidneys $(3.3 \%)$, and in some of the cases, the lesions were generalized. Earlier on Abubakar et al., (2010) in a similar study on TB in camels at the same abattoir reported examining the records of 500 slaughtered camels (Camelus dromedaries) using post mortem and Ziehl-Nelson staining and found $16.6 \%$ of the camels having lesions suggestive of being Mycobacterium species and that staining with Ziehl-Nelson staining demonstrated 8.3\% having Mycobacterium species.

The increasing prevalence levels from these studies indicates that there have been more incidences of the disease. The finding of cattle being infected with M. tuberculosis suggests possible interaction of these cattle with tuberculous humans. Ibrahim (2016) reported cattle being infected with $M$. tuberculosis in Bauchi and Gombe States. The migratory nature of pastoralists could have made such cattle from the North Eastern States of Nigeria to come to the North Western States for us to see such infections in these cattle. Similarly, the seeing of humans being infected with $M$. bovis could be as a result of close interaction of these humans with cattle (Ibrahim (2016). The attitude and practices of humans with regard to consuming unpasteurized milk and eating of poorly cooked meat could also result in humans coming down with the disease (Kaltungo, 2013; Ibrahim, 2016). Shehu (1988) reported humans being infected with $M$. bovis and the cattle he studied being infected with $M$. tuberculosis. There is therefore the need to look more closely on the surveillance of the disease before more infections being observed.

\section{Reports from North Eastern Nigeria}

One of the workers on bTB in the North Eastern part of Nigeria was Danbirni (2016) who carried out a survey of the disease in cattle and humans in Adamawa and Taraba States. Other researchers include Ibrahim (2016) and Saidu et al., (2015; 2017) among others. In his study, Danbirni (2016) reported isolating $M$. bovis and $M$. tuberculosis in cattle and humans and concluded that the disease is of economic importance in the Nigerian livestock industry. In the study, Danbirni (2016) reported prevalence rates in cattle as $8.4 \%$ in Adamawa State and $3.2 \%$ in Taraba State. He also demonstrated $34.8 \%$ detection rate of Mycobacterium species based on acid fast staining and isolation of the organisms from samples from patients' sputum from hospitals and herdsmen in the study areas.

Also, Ibrahim (2016), in a similar study of bovine TB (bTB) in Bauchi and Gombe States, Nigeria, examined 5,509 cattle using the single caudal fold intradermal tuberculin test (CFT) and found 232 $(10.96 \%)$ of the 2,116 cattle from Bauchi State positive for TB while 463 (13.73\%) of the 3,373 cattle from Gombe State were also positive for TB. He also reported the herd-based prevalence of bTB in Bauchi and Gombe States to be $56.04 \%$ and $55.29 \%$ respectively. In this study, he confirmed the existence of $M$. bovis, and M. tuberculosis in both cattle and humans using PCR. Other workers in Gombe State reported demonstrating M. bovis in cattle at the Gombe municipal abattoir and other slaughter houses using PCR (Saidu et al., 2015). Furthermore, Saidu et al., (2017), in a retrospective study of bovine tuberculosis in Gombe Township Abattoir from 2008 to 2015 using the abattoir post mortem inspection records reported that of the 154,562 slaughtered cattle under study, $1,202(0.78 \%)$ had typical tuberculous lesions and had overall prevalence rate of $0.78 \%$. The annual prevalence was significantly higher (1.04\%) in 2015 with the lowest recorded in 2011 being $0.34 \%$ Saidu $\boldsymbol{e t}$ al., (2017).

Raufu and Ameh (2010) in a survey to determine the prevalence of tuberculosis in cattle slaughtered in Maiduguri Central abattoir, using gross lesions during post mortem inspection reported that out of the 265,722 cattle slaughtered during the period of the survey, 2,902(1.1\%) were positive for pulmonary tuberculosis and that the annual prevalence during the study varied between $0.5 \%$ and $6.4 \%$. Similarly, Abubakar et al., (2010) in Maiduguri, Borno State carried out a retrospective study of bovine tuberculosis in Maiduguri abattoir between 2000 and 2009 when they reviewed records of 403,317 slaughtered cattle and found 11,006 cattle with lesions compatible with TB with lesions at the lungs (67.8\%), Lymph nodes (13.9\%), liver (8.6\%), intestines (3.8\%), kidneys $(4.0 \%)$ and others with generalized lesions (1.9\%). Some of the cattle slaughtered at the Maiduguri abattoir could have come from neighbouring countries of Chard and Niger Republics as there is regular influx of trade cattle from these countries into Nigeria (Raufu and Ameh (2010).

\section{Reports from North Central Nigeria}

Shima and Garba (2014) reported $3(0.8 \%)$ tuberculosis cases in pigs out of a number of lung diseases following post mortem inspection at a pig slaughter facility in Makurdi, Benue State. In a similar study in Benue State, Francis et al. (2014), while conducting a study on bovine tuberculosis in Oturkpo abattoir, Benue State, reported that $6.5 \%$ of the animals examined had TB lesions and that cows had more lesions (4.8\%) than bulls (1.6\%). Oragwa et al., (2017) in Jos, Plateau State following a retrospective study of Jos abattoir meat inspection records also reported that $8.59 \%$ of the cattle slaughtered during the period were diagnosed as having tuberculosis while 
$0.1 \%$ of the sheep, $0.1 \%$ of the goats had lesions suggestive of being for tuberculosis.

Regarding the distribution of the disease in the North Central part of Nigeria, Sani et al., (2015), in a study carried in Mina and Suleja areas of Niger State, using traditional methods on sputum of human patients confirmed demonstrating tubercle bacilli from the patients. The study revealed that $25.5 \%(153 / 600)$ of the studied participants were positive for Mycobacterium tuberculosis.

\section{Reports from South Western Nigeria}

Cadmus (2003), in a study of tuberculosis in food animals at the Ibadan and Abeokuta abattoirs, South Western Nigeria, reported that $6.7 \%$ of all the cattle he examined using Acid Fast stain and culture proved to be Mycobacterium species while none of the 67 sheep, was positive for TB. He, however, reported that one $(0.4 \%)$ of the 243 goats and $26(5.0 \%)$ of the 438 pigs were confirmed to have Mycobacterium species by AFS and culture.

Jenkins et al., (2011) in a study to determine the molecular epidemiology of tuberculosis in animals and humans in Ibadan at the Bodija abattoir and from human samples from tuberculosis patients and livestock traders at the Akinyele cattle market from 2005 to 2007 , identified 74 isolates out of which 4 were from humans and 70 were from livestock to be Mycobacterium tuberculosis Complex strains. They further tested 32 of the isolates using spoligotype of which 19 were identified as $M$. tuberculosis whilst 13 others were identified as Mycobacterium bovis. They reported that $M$. bovis was isolated from two humans, whereas $M$. tuberculosis was isolated from a bovine, a pig and a goat. As mentioned above the finding of $M$. tuberculosis in animals could be as a result of interaction of these cattle with humans just as is also the case in finding M. bovis in humans (Jenkins et al., (2011).

Other reports on tuberculosis in the South Western region of Nigeria include those of Odaibo $\boldsymbol{e t}$ al. (2013), Matthew et al., (2015) and Atiola et al., (2018) among others. Odaibo et al., (2013) observed a $12.3 \%$ HIV-TB co-infection rate in humans with tuberculosis in a multi-DOTS centre study in Oyo. A more recent four-year retrospective study in Ogun State by Kolade $\boldsymbol{e t}$ al., (2016) reported a 29\% prevalence of HIV co-infection in a cohort of TB patients. The same authors reported a $3.5 \%$ prevalence rate of TB among a separate cohort of HIV patients in Ogun State. These studies suggest a higher probability of HIV acquisition in TB patients than the observed rate of tuberculosis in HIV infected patients. In another study, Matthew et al. (2015) reported that $25 \%$ of the subjects in the study had HIV co-infection rate with tuberculosis. Similarly, Atiola et al., (2018) reported 5.1\% prevalence rate of HIV and $0 \%$ active tuberculosis among the human patients they studied. Among these patients were pregnant women which they observed were more likely to be exposed to blood transfusion with increasing risk of coming down with tuberculosis.

The demonstration of tuberculosis in both animals and humans in this region could indicate possible close interaction between animals and humans in a number of ways (Saidu $\boldsymbol{e t}$ al., (2017). Firstly, the disease surveillance and control of animal diseases, like in other parts of the country, have been very much left to be desired (Ahmad, 2015). Secondly, meat inspection regulations have not been strictly adhered to and this may result in contaminated meat with infectious agents like Mycobacterium species to be passed to humans and the subsequent infection in these humans (Saidu, 2017). This is particularly that most of the cattle and to a certain extent sheep and goats slaughtered in this region come from the North of the country and Ahmad (2015), Danbirni (2016), (Ibrahim (2016) and Saidu et al., (2017) variously reported high tuberculosis percent prevalence in the animals they studied and that they all confirmed presence of Mycobacterium species by PCR in the animals they studied in both North Western and North Eastern States of Nigeria.

Thirdly, the eating habits of Nigerians, whereby people eat partially cooked foods of animal origin like 'suya', 'balangu' and 'Kilishi' can add to the fear of transfer of infection from animals to humans, especially that Danbirni (2016) and Ibrahim (2016) among others have demonstrated $M$ bovis from the sputum of humans in their studies. Even in this region of the country, human cases of bTB have been demonstrated. The demonstration of $M$ tuberculosis in animals can also indicate possible interaction of animals with infected humans as Shehu (1988) reported demonstrating $M$ tuberculosis in 'Nono' from a herd whose owners were also found to have $M$ tuberculosis by using culture and AFS.

\section{Reports from South Eastern Nigeria}

Reports of tuberculosis in animals and humans in the South Eastern Nigeria include those of Onunkwo et al., (2003), Nwanta et al., (2011), Nwabuko et al., (2012), and Esien et al., (2016) among others. For example, Onunkwo et al., (2003) reported a prevalence of $2.7 \%$ in cattle slaughtered at Nsukka abattoir. In their own study, to generate epidemiological data on tuberculosis in cattle and humans in Enugu State, Nwanta et al., (2011), through a retrospective survey of abattoir and hospital records for a five-year period (2004 to 2008) examined a total 


\section{An overview of tuberculosis in Animals in Nigeria}

of 748 and 2452 records of tuberculosis cases in cattle and humans respectively. They reported that this finding made the State authorities to intensify control programmes against tuberculosis in both cattle and humans in the State.

\section{Reports from South Southern Nigeria}

To the best of our knowledge no reports of bovine tuberculosis was documented in the South Southern Nigeria. The reason for this may be attributed to low population density of livestock (Ibrahim 2016).

\section{Livestock owners' knowledge on tuberculosis}

The level of knowledge of livestock owners has a lot to do the occurrence of TB in animals and humans. For example, Damina et al., (2011), in a study to determine the knowledge of pastoralists on TB in Plateau State, Nigeria reported that $92.3 \%$ of the respondents were aware of the disease and they ascribed their sources of knowledge as people suffering from the disease. Among them $9.7 \%$ of the respondents were currently undergoing treatment against the disease and that they had a record of $16.1 \%$ having the disease at one time or another. They further reported that all $(100 \%)$ the community members who participated in the study were infected with TB and were on treatment against the disease. Similarly, in their study Lawan $\boldsymbol{e t}$ al., (2010) reported that butchers in four North Western States of Nigeria were not routinely examined for medical fitness before being engaged as butchers. Similarly, Yakubu (2016) reported many of the butchers had low educational level. These could account for the poor handling of carcasses along with the inadequate positive attitude and practices being observed in many abattoirs in Nigeria.

Danbirni (2016) in a study of the epidemiology of tuberculosis in cattle and humans in Adamawa and Taraba States, reported that only $18.4 \%$ of the respondents had good knowledge about the disease with $57.7 \%$ and $23.9 \%$ others having fair and poor knowledge on the disease respectively. Similarly, he reported that those with high education had better knowledge of the disease since those with tertiary education (33.4\%) had the highest knowledge with those with poor education (6.3\%) with lowest knowledge on the disease. Similarly, Ibrahim (2016), while working on the epidemiology of tuberculosis in cattle and humans in Bauchi and Gombe states, reported $72.0 \%$ of the respondents being aware of the disease and even had knowledge on the mode of transmission of the disease from cattle to humans and vice versa. The respondents similarly reported that some of their cattle that were coughing, were also emaciated to which the respondents believed that the coughing could have something to do with TB (Dahiru 2017).
In a study to determine the knowledge of rural dwellers and pastoralists on tuberculosis, Dahiru (2017) reported that $71.45 \%$ of the respondents were aware of the disease and that $74.60 \%$ of them knew Tuberculosis Treatment Centres. They associated their sources of knowledge to include Veterinarians (28.50\%), hospital friends (6.7\%), friends (4.56\%), fellow herdsmen $(3.37 \%)$, and the media $(31.25 \%)$. These sources have similarly been reported to be avenues for educating livestock owners on livestock diseases by Kaltungo (2013), Buhari (2014), Baba (2016) and Yakubu (2016). Many of the national radio stations routinely broadcast weekly livestock and human related programmes on health and production. Their knowledge on how cattle acquire TB included ingestion (16.80\%), drinking contaminated water (36.60\%), closeness to other infected animals (35.90\%), and from humans (10.49\%) (Dahiru, 2017). On their knowledge on whether humans also acquire TB from animals, $81.70 \%$ of the respondents agreed that humans can develop the disease and they indicated means of transmission to be through contaminated meat $(33.10 \%)$, contaminated milk (36.48\%) and closeness with infected persons $(30.40 \%)$.

As to their knowledge of signs of $\mathrm{TB}$ in animals, Dahiru (2017) reported that $61.48 \%$ of the respondents indicated coughing as the major sign of the disease with weight loss $(20.60 \%)$, death $(15.20 \%)$ and other unspecified signs (4.39\%). They also indicated signs of the disease in humans to be coughing (47.46\%), weight loss $(22.30 \%)$, fever $(17.06 \%)$ and death $(8.45 \%)$. In the study, Dahiru (2017) also enquired from the respondents whether the disease is zoonotic to which $71.45 \%$ of them indicated that animals could acquire the disease from man as well as humans acquiring the disease from animals $(74.15 \%)$. From above there is every indication that livestock owners in Nigeria can be said to be fairly aware of tuberculosis.

\section{Livestock owners' attitude on tuberculosis}

Damina et al., (2011), in a study to determine the pastoralists and rural dwellers' attitude towards tuberculosis in Plateau State reported that $51.6 \%$ and $10.0 \%$ of the pastoralists and community dwellers respectively were in a habit of consuming raw milk. They further reported that the milk and sputum of those who reported being on medication were negative for Mycobacterium by using Acid Fast Stain and PCR.

The attitude of livestock owners with regard to eating 'Suya' which is roasted meat in relation to tuberculosis was enquired by Dahiru (2017) in a study of the knowledge, attitude and practices of livestock owners to tuberculosis in Katsina State, Nigeria to 
which $81.41 \%$ of the respondents reported eating it daily while $12.66 \%$ and $5.91 \%$ others respectively indicated eating it once a week and once a month. The author similarly enquired on how the respondents drank milk to which $66.04 \%$ of them reported taking milk directly from the udder of cattle and that $35.10 \%$ of them considered that doing so had no effect on acquiring TB. Yet $30.4 \%$ others reported also drinking sheep and goat milk. This attitude certainly has direct effect of people acquiring TB should the animals be infected with the Mycobacterium species. In another study, Buhari (2014) reported pastoralists drinking milk directly from the udder of their cattle. Similarly, Kaltungo (2013) and Buhari (2014) variously reported respondents also eating 'Balangu' and 'Nono' both products being poorly heat-treated. In a situation whereby these meat products contain tubercle bacilli and are poorly treated by heat they could be an opportunity for the transmission of the disease to susceptible ones.

Furthermore, Kaltungo (2018a,); Kaltungo (2018b) reported people in Katsina and Sokoto states routinely taking "Nono' from cattle and camels with millet paste as a daily afternoon meal. Should such 'Nono' be contaminated with tubercle bacilli, there would be the possible transmission of the disease to them. The reports of Simon et al., (2009), Cadmus et al., (2006), Danbirni (2016) and Ibrahim (2016) among others in Nigeria have substantiated this view as Simon et al (2009) showed how people eating meat could come down with the disease.

With the poor meat inspection and surveillance programme along with inadequate to non-Veterinary heath care delivery in most nooks and corners of Nigeria along with the reports of the disease in animals and humans in all geopolitical zones of the country one would expect the ground to be ripe for the transmission of the disease through 'Suya' and even milk along with other livestock products (Danbirni, 2016). Many researchers have indicated that the tubercle bacilli can be demonstrated in meat and milk with unpasteurized milk being an important source of TB should the milk be contaminated with Mycobacterium species. Shehu (1988), Ahmad (2015), Danbirni (2016) and Ibrahim (2016) have reported demonstrating $M$. bovis, $M$ tuberculosis and M. africanum from milk of indigenous cattle in Nigeria.

\section{The effect of management practices on tuberculosis infection}

The livestock management practices in Nigeria, like in most African countries is extensive with the livestock (cattle, sheep, goats and pigs and even camels) being held by pastoralists and pig owners being found mostly in the country side (Saidu $\boldsymbol{e t}$ al.,
(1991); Dahiru, (2017); Kaltungo, (2018b). There are few elite farms that are managed semi-intensively (Danbirni, 2016); Danbirni (2018) with commercial poultry and pig production being largely intensive. Thus, the herding system warrants many herds to visit a particular grazing land many times and, in the process, meet other herds. Should any of the herds be infected with tuberculosis, such herds can also become infected. Dahiru (2017) reported herdsmen trekking for up to three kilometers for grazing daily and in such situations, they meet others herds. They also meet other herds at watering points (Kaltungo, (2018a); Dahiru, (2017). Such meeting could initiate transfer of tubercle bacilli as there may be close mixing and even breeding should any of the female animals be on heat. Many researchers like Dahiru (2017) and Kaltungo et al., (2017) and Kaltungo (2018a) have reported close habitation between animals and their owners. Should either of them be infected with tubercle bacilli, it is natural for disease transmission to take place. Furthermore, Lawan et al., (2010) and Dahiru (2017) reported pastoralists to be smoking while milking their cattle or processing animal carcasses. Thus, should the milk or carcasses be contaminated with tubercle bacilli, oral transmission of the disease could take place. The tradition of pastoralists to milk colostrum from dams that have newly calved and put it in the mouths of calves could trigger transfer of infection to such calves so long the milk contains tubercle bacilli. For example, Zanini et al., (1998) and Ozyigit et al., (2007) have suggested that ingestion of contaminated colostrum/milk could result in bTB transmission from cow to calf.

The risk is more glaring in Nigeria where it is common to see the herdsman milking a cow with bare hands and eating as he milks the cow (Dahiru, 2017). There could also be transmission of the disease from dam to calf as one can see the dam grooming its calf, especially during the first two weeks of calving. Phillips et al., (2003) suggested that transmission of TB could take place through close contact between a cow and its calf as it grooms the calf. In developed countries, however, where regular testing programmes are implemented and where outbreaks are rare, the risk may be considered negligible. Not only that in developed countries the calf is separated from its dam as the milk is collected for commercial production and calves are maintained in calf pens and are bucket fed with milk.

Pastoralists and even other Nigerians have the habit of socializing at night with friends and neighbours during which there could be eating, drinking and chatting. Furthermore, there are those that frequent night clubs and drinking parlors. Dahiru (2017) reported respondents doing so with friends 


\section{An overview of tuberculosis in Animals in Nigeria}

(42.22\%), brothers (12.60\%), sisters (5.22\%) and wives/husbands (39.23\%) and in some cases some of the members of the socialization $(5.50 \%)$ were coughing. Thus, should the coughing be due to tuberculosis, some of them could acquire the disease.

The management of abattoirs, slaughter houses and slabs in Nigeria is left much to be desired as there is hardly any serious routine meat inspection (Saidu $\boldsymbol{e t}$ al., 2015).

No wander most of the survey work done by researchers were at these locations and they all demonstrated presence of TB infected animals. These locations could serve as points for infection for humans, especially abattoir workers. For example, Lawan et al., (2010) reported that these butchers were seen smoking, eating freely and spiting during processing of carcasses at the abattoirs. They also reported butchers selling offals after washing such offals and meat to buyers at the abattoirs. They similarly reported that there were no hanging facilities for carcasses at these abattoirs as such all operations were conducted on rugged floors. Thus, even if such meat and offals were not contaminated with tubercle bacilli, they could be contaminated with other bacteria and should such meat be sold, buyers could come down with a number of diseases. Furthermore, the fact that there is no serious routine surveillance against diseases in both Veterinary and human facilities, especially in remote villages along with absence of routine tracing back on diseases, humans can continue to be infected from meat and meat products without any consideration of sources of the infections.

Similarly, Shehu (2019) and other workers reported that horses now find their way to slaughter houses in South Eastern Nigeria and some of the horses were demonstrated to have Brucella infection. Thus, it may not be impossible for such horses to also be infected with tubercle bacilli though there are very scanty reports on TB in horses in Nigeria. The fact that horses are imported from Sudan and other neighbouring countries, finding the disease in such horses cannot be ruled out (Ehizibolo et al., (2011). It could be that they also have tuberculosis judging from the fact that there is close relationship of horses with grooms as reported by and Baba (2019).

In Nigeria the traditional setting makes it to have many families within one enclosure. In such cases one sees a father staying in the same enclosure with his wives and sons who may also have wives and children (Buhari, 2014; Baba, 2016). There is also the evening and night talks among members of families. Where one member of the family is infected with tubercle bacilli, there is every chance for other members of the restricted and extended families to also acquire the infection.

Horse keeping in Nigeria has been an old tradition (Musa, 2013). They have various uses like ceremonial, polo, racing, leisure riding, youth having wedding horse riding and sugar cane extraction for the production of local sugar among others (Mshelia, 2013; Musa, 2013; Baba, 2016). The grazing pattern of pastoralists whereby they are always on the move could predispose to the spread of the disease from one location to another (Buhari 2014). The movement of pastoralists towards the south of Nigeria, which is gradually increasing as a result of cattle rustling and increasing desertification could see the disease surfacing in areas hitherto not known (Baba 2016).

For example, Nwachukwu et al., (2009) in Abia State and Okodua et al., (2004) in Edo State have both reported human and livestock infections and this could be due to this trend. Dahiru (2017) reported respondents having knowledge of the disease in their neighbouring herds but still intermingled with them at grazing and watering points, possibly due to poor attitude or not realizing the magnimity of the disease to their economy. Even within neighbours there could be the burrowing of a sire to serve a female animal on heat (Kaltungo, 2013; Buhari, 2014). Should the sire or any of the animals in that herd have tuberculosis, there would be the spread of the disease from one herd to another. Furthermore, Phillips et al., (2003) reported cattle can acquire infection through the oral route via regurgitation of the cud and in the process emit the organisms for aerosol transmission. Thus, the incoming sire could easily become infected or transfer the infection to the herd. Furthermore, Neill et al., (1988) reported that the animal might even inhale these contaminated aerosols and a subsequent respiratory infection can occur since as few as one bacillus can result in infection in an individual via the respiratory route.

Grazing grounds tend to be laboratories for many infectious agents. These grounds are used by local and migratory herds as in Nigeria there are approved grazing reserves and stock routes (Kaltungo 2013). There are also grazing corridors where herdsmen take their herds. In the village setting, small ruminants are seen roaming about and interact with one another (Kaltungo, 2013; Yakubu, 2016). Thus, at both grazing grounds and community grazing areas, animals could meet one another and transfer of infection could result so long any of the animals is infected.

The management practice of pastoralists in Nigeria allows the herder to keep his animals close to village settings and that the animals are gathered in 
kraals (an enclosure where animals are kept) (Buhari, 2014). Within these kraals, the cattle are tied in twos at night. This overnight staying allows for close contact among cattle. Not only that the small ruminants are tied in long ropes close to one another (Kaltungo, 2013; Buhari, 2014). In the same way calves are tied along long ropes away from their dams, as if they are left with the dam, the herdsman will not get any milk to sell the following day and for home consumption (Buhari, 2014). These practices tend to facilitate the spread of communicable diseases like tuberculosis. Ameni et al. (2006) and Menzies and Neill (2000) reported that transmission of bTB among animals is mainly aerogenic and that close contact between animals is a major risk factor for the disease.

Watering points tend to get animals congregated, especially during the dry season where water can only be obtained in water ponds (Buhari, 2014; Dahiru, 2016). Thus, the practice of pastoralists who do not have watering facilities for their individual herds run the risk of exposing their livestock to tuberculosis. Buhari (2014); Buhari (2019), Yakubu (2016) and Baba (2016); Baba (2019) all reported animals from different owners coming together and mix at watering points and associated the animals being positive for Brucella infection to this practice. The same could be for tuberculosis in these animals since it may be easier to become infected with tubercle bacilli through aerosol than with Brucella organisms which may to be through ingestion (Dahiru 2016).

Migration on its own is a good practice as it makes the herd owner to avoid disease as much as possible. However, in the process, the herdsman can enter an exposed area where his animals can contract diseases (Saidu et al., 1991). This is exemplified by nomadic transhumance that relies on the movement of livestock along with the owners to follow grazing and water points over considerable distances following seasonal changes. For example, during the rainy season, animals are taken to graze in natural pastures shared by several farmers and away from crop farms while during the dry season, several herds are seen to gather in mobile groups migrating together, and sharing grazing areas and watering sources together. As they migrate, they follow government approved stock routes that could link them from one state to another and from one Local Government Area to another within the same state. However, transhumance has recently been associated with an increased bTB status in Zambia (Munyeme et al., 2008).

Introduction of new animals by farmers of both small and large ruminants has been variously reported by researchers (Kaltungo (2013); Buhari (2014); Yakubu (2016). Baba (2016); Baba (2019) also reported horse owners introducing new horses to their stables as he also reported culling unwanted animals and horses in their herds/stables. They were also reported not to isolate or quarantine such newly added animals to ensure them be free of any infection. In a situation where any of such introduced animals is tuberculous, there is every chance that the disease will be introduced to the regular animals in the herd/stable (Yakubu 2016). This is more so that if the animal is incubating the disease or the disease is at its initial onset as the new owner buying it may not be that educated as to notice the signs of the disease at the time of purchase. Livestock traders have the tradition of treating their animals with the hope that such animals will be healthier as they take them to the market (Dahiru, 2017). Thus, this treatment could temporarily subdue the infection before it resurfaces after purchase.

In Nigeria, there are many types of breeding systems as practiced by livestock owners. For example, some farmers use only their own sires and never allow sires from outside the herd (Kaltungo, 2013; Buhari, 2016). There are also others who, traditionally, do not own sires but rely on burrowing them or taking their females on heat to a sire in another herd. There are also states who have Livestock Investigation and Breeding Centres (LIBCs) and encourage livestock owners to take their females for breeding (Saidu et al., 1991). Thus, it will be easy to transfer and even spread tuberculosis should any of the animals be tuberculous. The spread may even not be restricted but could result in the dams being bred to pass on the infection to her calf as Ozyigit et al., (2007) described vertical transmission of $M$. bovis from an infected dam to her calf through congenital infection in-utero. The same situation can occur if the sire is lent to other famers (Buhari, 2014). Saidu et al., (2017) reported pastoralists organizing mating of their animals at grazing and watering points while Yakubu (2016) reported small ruminants' owners allowing their animals to breed among themselves at community streets.

The Husbandry and management practices of horses in Nigeria have avenues for making it possible for tuberculosis to strive among horses and even their handlers if the disease is circulating among them. For example, horses have chances to meet and interact among themselves during polo and racing tournaments (Baba, 2016). Similarly, the occasional ceremonial gatherings of horses during religious festivals and the weekly durbar for youths during marriages all make it possible for TB transmission as infected horses will be releasing tubercle bacilli droplets in aerosols which can move from one horse to another and even to humans (Musa, 2013). The prevalence of TB in horses from Nigeria is scanty. Due to this scanty information, it is 


\section{An overview of tuberculosis in Animals in Nigeria}

difficult to ascertain role of horses in the spread of the disease to another animal.

In Nigeria dairy production is fast gaining ground with governments increasingly encouraging Nigerians to take up agricultural production, livestock development inclusive. Thus, many dairy outfits, especially for yoghurt production are springing up by the day. Thus, every effort must be made to raise TBfree cattle for this purpose. For now, the traditional milk in the form of soured milk ("Nono') and butter are the main sources of milk products in Nigeria. Shehu (1988) along with other workers have shown that these dairy products could contain tubercle bacilli. Thus, these products can serve as means of transmission of the disease from animals to man. In Nigeria, Alhaji (1976), Shehu (1988), Danbirni (2016) and Ibrahim (2016) have abundantly shown that these dairy products could contain the organisms as they demonstrated $M$. bovis, $M$. tuberculosis and $M$. africanum in dairy products.

The climate and vegetation in Nigeria are varied from the North to the South of the country. For example, during the rainy season it can be very wet and fairly cold as to allow the survival of bacteria that can infect animals and man like Brucella spp and members of the Mycobacterium tuberculosis complex outside the host (Philips et al., 2003; Buhari, 2019). Similarly, during the dry season it can be dry and severely cold, especially in the far North of the country as not to allow the survival of bacteria for long. There is also midway situation of coldness and extreme heat during certain parts of the year. With these situations, it is possible to see the facilitation of the maintenance of bacteria outside the host, especially if they are found in tissues of dead animals as to survive and get transmitted to animals. Thus, should an animal abort and there is vertical transmission of tubercle bacilli as reported by Zanini $\boldsymbol{e t}$ al., (1998) and Ozyigit $\boldsymbol{e t}$ al. (2007) the aborted foetus could have infection. Thus, should a dog happen to pick the aborted foetus after being disposed by the owner as reported by Kaltungo (2013) and Buhari (2014) and other workers, the organisms can be spread along the distance the dog might carry it to result in infection in the dog or any other animal that might graze on the roughage where the foetus is drugged on.

However, the survival of $M$. bovis outside living animals is controversial as Menzies and Neill (2000) stated that $M$. bovis is able to survive in the environment for only a few weeks under natural conditions, considering that environmental contamination is a less effective means of disease transmission to cattle. Jackson et al., (1995) reported that the surroundings of watering points tend to get wet because of the splashing of water by animals as they come to drink water. In the process, should any of the animals be infected some of the aerosols from them can be deposited on the moist environment and there after cause infection in the next set of animals that come to drink water. Philips et al., (2003) suggested that splashing could favour the entry of the bacilli into the respiratory tract of animals that come to drink water through inhalation of contaminated droplets. In recent years, flooding took place almost annually in Nigeria. In such cases, flood water could take live animals and dead ones to far distant locations. Should any of the animals be tuberculous, such animals or dead animals could be avenues for the spread of the disease. Cleaveland et al., (2007), in a cross-sectional study showed that flooding could serve as a spreading factor for $M$. bovis in the environment and suggested that this role can be dictated by the mean daily temperature.

\section{CONCLUSIONS}

This review had documented that tuberculosis occurred in both animals and humans in Nigeria. There is the need to implement sound control and eradication programmes in the country, as well as ensure use of improved standards of meat inspection. In addition to reducing transmission through food chains and direct contact, efforts on public enlightenment campaigns regarding potential dangers of the disease should be undertaken.

\section{Conflict of interest}

The authors declare that there is no conflict of interest

\section{REFERENCES}

ABUBAKAR, U.B., KUDI, A.C., ABDULKADIR, I.A. OKAIYETO, S.O. AND IBRAHIM, S., 2012. Prevalence of Tuberculosis in Slaughtered Camels (Camelus dromedaries) Based on Post-Mortem Meat Inspection and Ziehl-Nielsen Stain in Nigeria. Journal of Camel Practice and Research, 19: 29-32.

AHMAD, I., 2015. Survey of tuberculosis in slaughtered cattle in Gusau abattoir, Zamfara State, Nigeria. MSc Dissertation, Ahmadu Bello University. Pp 1-0167.

AHMAD I, KUDI C.A, ABDULKADIR A.I, SAIDU S.N.A., 2017. Occurrence and distribution of bovine TB pathology by age, sex, and breed of cattle slaughtered in Gusau abattoir, Zamfara State. Trop. Anim. Health Prod. 49(3):583-589.

ALAN, K.K., WEAVER, M.R., OGUNGBEMI, M.K., ASHEFOR, G., ANENIH, J. AND ADEYEMI, A., 2016. Prevalence of tuberculosis and HIV/AIDS coinfection among HIV clients at global fund supported comprehensive facilities in Nigeria. International Journal of Research in Medical Science 4 (6). 91-95.

ALHAJI, I., 1976. Bovine tuberculosis in four Northern States of Nigeria. PhD Thesis, Ahmadu Bello University, Zaria, Nigeria. Pp 1-236. 
ALIYU, S.U., 1990. Sheep and goat production. Extension Bulletin No. 46, Livestock series No. 5 published by National Agricultural Extension Research Liaison Services, Ahmadu Bello University, Zaria. Pp 1- 24.

AMENI, G., ASEFFA, A., ENGERS, H., YOUNG, D., HEWINSON, G. AND VORDERMEIER, M., 2006. Cattle husbandry in Ethiopia is a predominant factor affecting the pathology of bovine tuberculosis and gamma interferon responses to mycobacterial antigens. Clinical and Vaccine Immunology 13:1030 1036.

AMEEN SA, ADEDEJI OS, RAHEEM AK, LEIGH OO, RAFIU TA, AND IGE AO., 2008. Current Status of Bovine Tuberculosis in Ogbomoso Area of Oyo State. Middle-East Journal of Scientific Research 3 (4): 207-210.

ATILOLA, G., RANDLE, R., TOMISIN, O.O., ISAAC, O., KOMOLAFE, I.O. AND ADENUGA, L., 2018. Epidemiology of HIV and Tuberculosis in pregnant women, South West Nigeria. Journal of Infection and Public Health, 11(6): 826-833.

BABA, A.Y., 2016. Prevalence of Brucella antibodies in Horses and Knowledge, Attitude and practices of Grooms in Three Local Government Areas of Kaduna State, Nigeria. M.Sc. Dissertation, Ahmadu Bello University, Zaria, Nigeria. Pp 1-135.

BABA, A.Y. .2019. Clinico-epidemiological studies of Brucellosis in Kano metropolis, Kano State, Nigeria. PhD Thesis, Ahmadu Bello University, Zaria, Nigeria. Pp1-190.

BROSCH, R., GORDON, S.V., MARMIESSE, M., BRODIN, P., BUCHRIESER, C., EIGLMEIER, K., GARNIER, T., GUTIERREZ, C., HEWINSON, G., REMER, K., PARSONS, L.M., PYM, A.S., SAMPER, S., van SOOLIGEN, D. and COLE, S.T., 2002. A new evolutionary scenario for the Mycobacterium tuberculosis complex. Proceeding of the National Academy of Science, USA. 99: p.6843689

BUHARI, H. U., 2014. Survey of bovine brucellosis in the North Senatorial district of Kaduna Statem, Nigeria MSc thesis to Ahnmdu Bello University, Zaria, Nigera. 111 pages.

BUHARI, H. U., 2019. Epidemiology of Brucella species in small ruminants in institutional farms and a slaughter slab in Zaria, Kaduna State, Nigeria. $\mathrm{PhD}$ thesis Ahmadu Bello University, Zaria, Nigeria 138 pages.

CADMUS, S., PALMER, S., OKKER, M., DALE, J., GOVER, K., SMITH, N., JAHANS, K., HEWINSON, R.G. AND GORDON, S.V., 2006. Molecular analysis of human and bovine tubercle bacilli from a local setting in Nigeria. Journal of Clinical Microbiology, 44: 29 - 34.

CADMUS, S.I.B., 2003. Tuberculosis in food animals. Nigeria Veterinary Journal, 24 (3): 72-75.

CADMUS, S. AND ADESOKAN, H., 2009. Causes and implications of bovine organs/offal condemnations in some abattoirs in Western Nigeria. Tropical Animal Health and Production, 41, 1455--1463.

CLEAVELAND S, SHAW DJ, MFINGA SG, SHIRIMA G, Kazwala RR, EBLATE E, SHARP M., 2007. Mycobacterium bovis in rural Tanzania:risk factors for infections in human and cattle populations.
Tuberculosis

$87(1): 30-43$

doi: 10.1016/j.tube.2006.03.001.

COSIVI O, GRANGE JM, DABORNE CJ, RAVIGLIONE MC, FAJIKURA T, COUSINS D., 1998. Zoonotic tuberculosis due to Mycobacterium bovis in developing countries. Emerging Infectious Diseases 4: 59-70.

DAHIRU, M.H., 2017. Determination of epidemiological factors associated with bovine tuberculosis in selected Local Government Areas of Katsina State, Nigeria. Master in Tropical Veterinary Medicine, Ahmadu Bello University, Zaria, Nigeria. Pp 1-128.

DAMINA, M.S., OWOLODUN, O.A., CHUKWUKERE, AMEH, J.A. AND ALIYU, M.M., 2011. Mycobacterium species identification and public health implication of tuberculosis among pastoralists in three Local Government Areas of Plateau State, North Central Nigeria. Nigerian Veterinary Journal, 32 (4): 321-330.

DANBIRNI, S., 2016. Epidemiology of tuberculosis in cattle and human patients in Adamawa and Taraba States, Nigeria. PhD thesis, Ahmadu Bello University, Zaria, Nigeria. Pp 1-170.

DANBIRNI, S., 2018. Survey of haemoparasites and assessment of farm management risk factors enhancing haemoparasitism in pastoralist and sedentary cattle herds in Soba Local Government Area, Kaduna State, Nigeria. Pp 1-59.

DAVID EHIZIBOLO,P.O EHIZIBOLO,AND M.Y IDACHABA, 2011. The Control of Neglected Zoonotic Diseases in Nigeria through Animal Intervention. African Journal Biomedical Research 14(2.)

ESSIEN M. K, JONAH B.O, EKATTE E.E, and UDEME I.T., 2016. Prevalence of tuberculosis in Calabar, Nigeria: A case study of patients attending the outpatients Department of Dr. Lawrence Henshaw Memorial Hospital, Calabar. Saudi Journal for Health Sciences 5(3):13.

EUROPEAN FOOD SAFETY AUTHORITY., 2011. The European union summary report on trends and sources of zoonoses,zoonotic agents and food bourne outbreaks in 2009.EFSA J.,2011 9(3):2090.

FOOD AND AGRICULTURE ORGANIZATION OF THE UNITED NATIONS ROME, 2019. Africa Sustainable Livestock 2050. Pp 12-14.

FRANCIS E. E., ADESHOKAN H. K., RAJI M. A., BELLO M., MUSA J. A., KUDI, A. C. and CADMUS, S. I. B., 2014. Current Status of Bovine Tuberculosis in Otukpo. Nigeria. J Anim Pro Adv 4 (8):501-507

GARBA, A., AHMED, A., AMBURSA, A.U., BARDE, J.L., ABDULAZEEZ, N.D., SULEIMAN, U., DANJUMA, H.U., USMAN, B.U., FAROUK, A. AND ATUMAN, Y.J., 2010. Common diseases of sheep and gpoats in Birnin Kebbi, Kebbi State, Nigeria. Paper presented at Nigerian Veterinary Medical Association Annual Congress held at Auditorium, College of Health Sciences, Benue State University, Makurdi between $4^{\text {th }}$ and $8^{\text {th }}$ October, 2010.

GRANGE, J.M., 1996. The biology of the genus Mycobacterium. J. Appl.Bact. Symp.Supp,81:1s-9s 


\section{An overview of tuberculosis in Animals in Nigeria}

GRANGE D.M., 2001. Mycobacterium bovis infection in human beings. Tuberculosis 8 (1-2): 71-77

HADDAD, N., MASSELOF, M. and DURAND, B., 2004. Molecular differentiation of Mycobacterium bovis isolates. Review of main techniques and applications. Research in Veterinary Science, 76: 1-18.

IBRAHIM, S., 2016. Epidemiology of Tuberculosis in Cattle and Human Patients in Bauchi and Gombe States, Nigeria. PhD thesis, Ahmadu Bello University, Zaria, Nigeria. Pp 1-149.

IGBOKWE, I.O., MADAKI, I.Y., DANBURAM, S., AMEH, J.A., ALIYU, M.M. AND NWOSU, C.O., 2001. Prevalence of pulmonary tuberculous lesions in cattle slaughtered in abattoirs in Northeastern Nigeria. Evue d'elevage et de medicine veterinaire des pays tropicaux, 54: 191-194.

JACKSON R, deLISLE GW, MORRIS R.S., 1995. A study of the environmental survival of Mycobacterium bovis on a farm in New Zealand. New Zealand Veterinary Journal. 43:346-52. doi: 10.1080/00480169. /1995.35918

JENKINS, A.O., CADMUS, S.I.B., VENTERE, E.H., POURCEL, C., HAURE, Y., VERGNAUD, C. AND GODFROID, J., 2011. Molecular epidemiology of human and animal tuberculosis in Ibadan, Southwestern Nigeria. Veterinary Microbiology, 151: $139-147$.

KALTUNGO, B.Y., 2013. Survey of brucellosis in Sheep and Goats in Kaduna North Senatorial District of Kaduna State, Nigeria. M.Sc. Thesis, Ahmadu Bello University Zaria. Pp 1- 155.

KALTUNGO, B.Y., 2018a. Serological and Participatory Studies of Brucella infections in Small ruminants in Katsina and Sokoto States, Nigeria. Ph.D. Thesis, Ahmadu Bello University Zaria. Pp 1-143.

KALTUNGO, B.Y., 2018b. Sero-prevalence and risk factors for Brucella melitensis in camels in two Local Government Areas of Katsina State, Nigeria. Project submitted to College of Veterinary Surgeons Nigeria for the award of Fellow, College of Veterinary surgeons Nigeria. Pp 1-56.

KALTUNGO, B.Y., BABASHANI, M., SAIDU, S.N.A., BUHARI, H.U. AND BABA, A.Y., 2017. Survey of pastoralists' knowledge, attitude and practices with regard to brucellosis in selected Local Government Areas of Kaduna State, Nigeria. Paper presented at the Annual Congress of Nigerian Veterinary Association held between $6^{\text {th }}$ and $10^{\text {th }}$ November, 2017 in the Coronation Hall, Government House Kano, Kano State, Nigeria.

KOLADE, R.J.G., ATILOLA, V. AND BABALOLA, O.K., 2016. HIV-TB co-infection and associated risk factors among HIV positive patients at Olabisi Onabanjo University Teaching hospital, Ogun state South west Nigeria, 15 (2): 69-72.

KUZE, F and UCHIHIRA, F., 1984. Various colony formers of Mycobacterium avium intracellulare.Euro.J.Resp Dis.65:402-410.

LAWAN, M.K., BELLO, M. AND RAJI, M.A., 2010. The public health implications of the operational activities of butchers in abattoirs. Paper presented at the Nigerian Veterinary Medical Association Annual Congress held vat the Auditorium, College of Health
Sciences, Benue State University, Benue State, Nigeria $4^{\text {th }}-8^{\text {th }}$ October, 2010.

MATTHEW, A.O., GBENGA, A.O., OLAMIDE, S.O., ADERONKE, A., GANI, I.M. AND NNAMDI, O. 2015. Tuberculosis and HIV coinfection among patients attenting directly observed treatment short course (DOTS) in Lagos Nigeria, 7 (7), pp. 69-74.

MENZIES, F.D. AND NEILL, S.D., 2000. Cattle-to-cattle transmission of bovine tuberculosis. Veterinary Journal, 160:92-106.

MSHELIA, P.W., 2013. Seroprevalence of African Horse Sickness in Kaduna State. MSc Thesis, Ahmadu Bello University, Zaria, Nigeria.

MUNYEME, M., MUMA, J.B., SJKERVE, E., NAMBOTA, A.M., PHIRI, I.G.K. AND SAMUI, K.L., 2008. Risk factors associated with bovine tuberculosis in traditional cattle of the livestock/wildlife interface areas in the Kafue basin of Zambia. Preventive Veterinary Medicine, 85: 317328.

MUSA, G.A., 2013. Prevalence of haemo- and gastrointestinal parasites of horses in Jigawa State, Nigeria. MSc Thesis, Ahmadu Bello University, Zaria, Nigeria. Pp20 - 34 .

NEILL， S.D., HANNA， J., O'BRIEN, J.J. AND MCCRACKEN, R.M., 1988. Excretion of Mycobacterium bovis by experimentally infected cattle. Veterinary Record, 123:340-343.

NWABUKO, C.O., EJELE, O.A., CHUKU, A., NNOLI, M.A. AND CHUKWUNONYE, I.I., 2012. Prevalence of Tuberculosis-HIV coinfection and relationship between Tuberculosis and CD4/ESR in HIV patients in Niger Delta Region of Nigeria ISOR Journal of Dental and Medical Sciences, 2 (4).

NWACHUKWU, N.C; ORJI, A; KANU, I. AND OKEREKE, H.C., 2009. Epidemiology of Pulmonary Tuberculosis in Some Parts of Abia State, Federal Republic of Nigeria. Asian Journal of Epidemiology, 2: $\quad$ 13-19. DOI: 10.3923/aje.2009.13.19

NWANTA, J.A., UMEONONIGWE, C.N., ABONYI, G.E. AND ONUNKWO, J.I., 2011. Retrospective study of bovine and human tuberculosis in abattoirs and hospitals in Enugu State, Southeast Nigeria. Journal of Public Health and Epidemiology, 3 (7): 329-336.

ODAIBO, G., OKONKWO, P., LAWAL, O. AND OLALEYE, D., 2013. HIV infection among newly diagnosed TB patients in Southwest Nigeria: a multiDOTS center study World Journal of AIDS, 3 (2):154-159.

OKODUA, M.A., NWOBU, G.O., TATFENG, Y.M., ONGEY. J.Y. AND AGWU, E., 2004. Incidence of HIV-Related Pulmonary Tuberculosis in Edo State, Nigeria. Shiraz Electronic Medical Journal (SEMJ), 5(1). www.semj.sums.ac.ir/vol5/jan2004/current.htm. Accessed on $14^{\text {th }}$ December, 2009.

ONUNKWO, T.F., WZEOKONKWO, R.C. AND OBIEGBULEM, S.I., 2003. Observations made during meat inspection at the main abattoir, Nsukka, Nigeria. Nigerian Veterinary Journal 24 (3): 52-56.

ORAGWA, A.O., OZIEGBE, S.D., PATROBAS, M.N., DUNKA, H.I., BUBA, D.M. and GURUMYEN, 
Y.G.1., 2017. Prevalence of Tuberculosis among Livestock Slaughtered for Human Consumption: A Jos Abattoir Based Study. Saudi Journal of Medical and Pharmaceutical Sciences, 3 (7B):777-783.

O"REILLY,L.M.and DABORN,C.J., 1995. The epidemiology of Mycobacterium bovis infection in animals and man:a review.Tuberc.Lung Dis.,76:1146.

OZYIGIT, M.O., SENTURK, S. AND AKKOC, A., 2007. Suspected congenital generalized tuberculosis in a newborn calf. Veterinary Record, 160:307-308.

PHILLIPS, C.J.C., FOSTER, C.R.W., MORRIS, P.A. AND TEVERSON, R., 2003. The transmission of Mycobacterium bovis infection in cattle. Research in Veterinary Science, 74:1-15.

RAUFU, I.A. AND AMEH, J.A., 2010. Prevalence of bovine tuberculosis in Maiduguri, Nigeria: An abattoir. Bulletin of Animal Health and Production Africa, 58 (2): 119-123.

SAIDU, A.S., MUSA, A., MUHAMMAD, M., GASHUA, M.B., MAHRE, A. AND MAIGADO, I., 2017. Retrospective study of bovine tuberculosis in Gombe Township abattoir, Northeastern Nigeria. International Journal of Veterinary Science and Medicine, 5 (1): 65-69.

SAIDU, S.N.A., UMARU, M. AND ALIYU, S.U., 1991. Husbandry, health management and socio-economic practices of pastoralists in selected states of Nigeria. Paper presented at the Nigerian Society for Animal Production Annual Conference held at Sokoto, March, 1991.

SAIDU AS, OKOLOCHA EC, GAMAWA AA, BABASHANI M, BAKARI N.A., 2015. Occurrence and distribution of bovine tuberculosis (Mycobacterium bovis) in slaughtered cattle in the abattoirs of Bauchi State, Nigeria. Veterinary World, $8(3): 432-437$.

SANI R. A., GARBA S. A., OYELEKE S. B., ABALAKA M. E., 2015. Prevalence of Pulmonary Tuberculosis (PTB) in Minna and Suleja Niger State, Nigeria. American Journal of Medicine and Medical Sciences 5 (6): 287-291

SHEHU, L.M., 1988. Survey of tuberculosis and tubercle bacilli in Fulani herds, 'Nono' and some herdsmen in Zaria Area, Nigeria. MSc thesis, Ahmadu Bello University, Zaria, Nigeria. Pp 1-118.

SHIMA, F.K. AND GARBA, H.S., 2014. Prevalence of characteristic macroscopic lung pathologies in pigs at slaughter in Makurdi, Benue State, Nigeria. Bulletin of Animal Health and Production in Africa, 62 (4).

SIMON, I. C., HEZEKIAH, K.A., AND DICK VAN, S., 2009. Mycobacterium bovis and M. tuberculosis in Goats, Nigeria. Emerging infectious Diseases, 15 (12):2066-2067.

THOEN C.O. and BLOOM B.R., 1995. Pathogenesis of Mycobacterium bovis. In:(C.O. Thoen and J.H. Steele eds.,), Mycobacterium bovis infection in animals and humans. Ames Iowa State Press. Pp. 3-14.

USMAN B. A, AMEH J. A, ABDULKADIR I. A, IBRAHIM S., 2011. Bovine Tuberculosis: A review. Veterinary Record :24-27 DOI:10.3923/vr.2011.24.27

WORLD HEALTH ORGANIZATION (WHO). Global Tuberculosis report,http:// www.who.int/tb/ publications/ global_report/en/; 2017. Accessed 19 March 2018.

YAKUBU, Y.B., 2016. Seroprevalences of Brucella in small ruminants, knowledge, attitude and practices of small ruminant owners in Kaduna metropolis, Kaduna State, Nigeria. MSc thesis, Ahmadu Bello University, Zaria, Nigeria. Pp1-119.

ZANINI, M.S., MOREIRA, E., LOPES, M.T., MOTA, P. AND SALAS, C.E., 1998. Detection of Mycobacterium bovis in milk by polymerase chain reaction. Journal of Veterinary Medicine Series B, 45:473-479.

How to cite this article:

Ibrahim, S. ${ }^{1}$; Kaltungo, B. Y. ${ }^{2}$; Buhari H. U. ${ }^{3}$; Baba, A. Y. ${ }^{4}$; Saidu, S. N. A. ${ }^{1}$; Mohammed, F.U. ${ }^{2}$ and Dahiru, M. $\mathbf{H}^{5}$., 2021. An overview of tuberculosis in Animals in Nigeria. Journal of Applied Veterinary Sciences, 6 (3): 7 - 19. DOI:https://dx.doi.org/10.21608/javs.2021.74906.1078 